\title{
Preliminary modeling of the oil trapping between teeth for spur gears
}

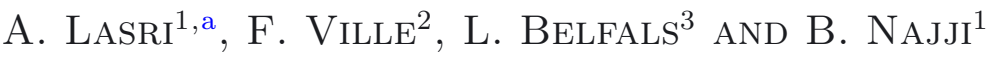 \\ 1 Laboratoire de Mécanique, Thermique et Matériaux (LMTM) de l'ENIM, Agdal, Rabat, Maroc \\ 2 Laboratoire de Mécanique des Contacts et des Structures (LaMCoS) de l'INSA de Lyon, France \\ 3 Laboratoire de Qualité, Sécurité et Maintenance de l'EMI, Agdal, Rabat, Maroc
}

Received 7 July 2013, Accepted 28 May 2014

\begin{abstract}
This study focuses on the phenomenon of oil trapping in the tooth spaces of spur gears. It presents the first obtained results in order to provide an estimation of the power losses due to the compression of the oil trapped between the inter teeth meshing spaces in a high-speed transmission for internal and external spur gears. It first allows, to model the inter teeth spaces at any time and offers limits for the trapped fluid volume and axial and radial discharge surfaces. The discretization impact result is discussed.Then, the influence of certain design and operating parameters such as module, pressure angle, addendum modification coefficient and rotational speed on these discharge surfaces and trapped volume is presented.
\end{abstract}

Key words: Design parameter energy losses / gear transmission / operating parameter / trapping

\section{Introduction}

In gear transmissions, tooth lubrication is necessary to cool surfaces. However, during the meshing of highspeed gears, the trapping loss is the term used to depict the fluid which is successively compressed and expanded in the inter-teeth spaces giving rise to significant heating and power.

Several studies on gears try to prevent their deterioration, to improve performance and minimize power losses. These may be due to frictions (friction loss) [1] or in relation to ambient air via the ventilation phenomenon called aerodynamic losses (windage loss) [2] or in connection with lubricant that depends on the type of lubrication, this is the case of losses by churning (churning loss) or by trapping fluid between gear teeth at high rotational speeds (trapping loss). Several studies have been interested in churning losses as [3], and researches in this case are even more advanced and models are proposed to calculate the churning losses [4]. But there are only few available published studies on the modeling of oil trapping between mating gears.

This study focuses on trapping phenomenon and contributes to the understanding of what happens between the teeth at high speeds while trying to give an estimation

${ }^{a}$ Corresponding author: lasri_enim@yahoo.fr of the power loss due to the compression of the trapped fluid.

Previous studies have shown an increase in pressure and temperature of the fluid between gear teeth [5]. Also, the noise generated by the fluid trapped in gears at high speed, was noticed by Smith [6]. This noise due to trapping for the case of air was confirmed by Houjoh et al. [7]. The study of gear losses (overall and for different loss types such as friction, windage and trapping) was treated by Diab et al. [8,9]. The three types of losses were compared under different operating conditions. At low-speed friction losses are the most important while windage and trapping losses are very low. At high speed, the last ones become significant. Hohn et al. [10] proposed a model of gear tooth profile referred by low loss gear. These models reduce friction loss by changing design parameters of tooth profiles. Three types of modified gear profiles were tested by Magalhaes et al. [11].

To contribute in the gear deterioration solving problems and the performance improvement, there is a need for highlighting what happens in the inter tooth during meshing. To meet this need, a numerical model is developed to calculate the control volume of the trapped fluid in the inter tooth and determine the surfaces limiting this volume depending on the rotational angle. The numerical model allows checking the influence of some design and operating parameters on inter tooth. In the field of pumps, the example of the gear pump BARNES that uses 


\section{Nomenclature}

\begin{tabular}{|c|c|}
\hline$a$ & Center distance $[\mathrm{mm}]$ \\
\hline$b$ & Face width $[\mathrm{mm}]$ \\
\hline$c$ & $\begin{array}{l}\text { Gear clearance between tooth } \\
\text { tip and wheel root }[\mathrm{mm}]\end{array}$ \\
\hline$h a$ & The addendum coefficient \\
\hline$h f$ & The deddendum coefficient \\
\hline$m$ & Module $[\mathrm{mm}]$ \\
\hline$M$ & Point on the involute \\
\hline$N p t$ & Number of points on the involute \\
\hline Nps & Number of equal angles $\Delta \theta$ \\
\hline$R a 1$ & Outer radius of the pinion $[\mathrm{mm}]$ \\
\hline Ra2 & Outer radius of the gear $[\mathrm{mm}]$ \\
\hline$P e(x e, y e)$ & Point of the starting meshing \\
\hline Ps & Point of the end meshing \\
\hline$r b$ & Base radius $[\mathrm{mm}]$ \\
\hline$r p$ & Pitch radius $[\mathrm{mm}]$ \\
\hline$S a$ & Axial leak surface $\left[\mathrm{mm}^{2}\right]$ \\
\hline $\operatorname{Sr} 1$ & Radial leak surface (left) $\left[\mathrm{mm}^{2}\right]$ \\
\hline Sr2 & Radial leak surface (right) $\left[\mathrm{mm}^{2}\right]$ \\
\hline$V$ & Initial fluid volume $\left[\mathrm{mm}^{3}\right]$ \\
\hline$v$ & Outlet fluid volume $\left[\mathrm{mm}^{3}\right]$ \\
\hline$x$ & Addendum modification coefficient $[\mathrm{mm}]$ \\
\hline$\alpha$ & Pressure angle $[\mathrm{deg}]$ \\
\hline$\Delta \theta$ & Angle between two positions $\left[^{\circ}\right]$ \\
\hline
\end{tabular}

small radial holes which convey the trapped fluid to the discharge port, allows avoiding the problem of entrapment and increasing the fluid pressure in the inter teeth.

Some works such as Concli [12], Mauz [13] and Seetharaman [14] were also interested in power losses in gears; they separated the terms depending on the load and others independent of load. Concerning no load losses, some are due to compression of the fluid trapped between the gear teeth. To estimate these losses, Concli tried to calculate the compressed fluid volume. The limits of this volume of fluid proposed by Concli consider the nearest distance between one side of the vertices of a tooth and the other side as one of the sides. The novelty of the present work is that it offers the closest side between the flanks of inter teeth.

This contribution is divided in three steps. The first one is dedicated to the study of geometry and will permit the description of the gear geometry during meshing and determine the limits of control volume of the trapped fluid as well as its free boundaries. It will be limited to cases of involute gear for external and internal spur gears.

The second step will show the influence of the discretization fineness on the obtained results.

The third step is devoted to the determination of the design such as module, pressure angle, addendum modification coefficient and operating parameters influencing the trapping phenomenon.
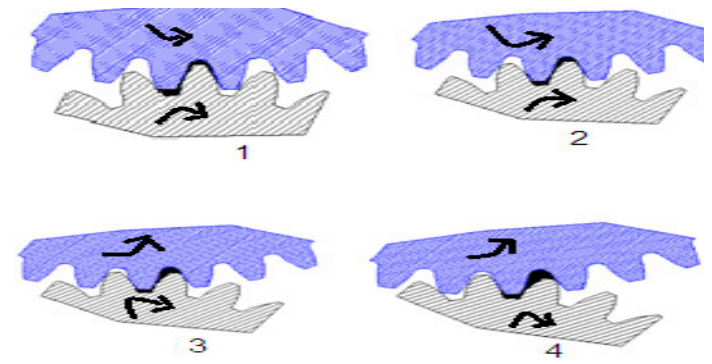

Fig. 1. Trapping oil phenomenon.

Table 1. Gear 1.

\begin{tabular}{cccccc}
\hline & $r p$ & $m$ & $\alpha$ & $x$ & $b(\mathrm{~mm})$ \\
\hline Pinon & 100 & 10 & $20^{\circ}$ & 0.2 & 100 \\
wheel & 200 & 10 & $20^{\circ}$ & -0.2 & 100 \\
\hline
\end{tabular}

\section{Description of trapping phenomenon}

The Figure 1, where the direction of rotation is shown, presents meshing steps in a gear transmission between a pinion and a wheel.

To simplify the problem, it will be assumed that, initially, the pinion deddendum before engagement with a tooth of the wheel is filled with fluid and have a volume $V$. (In fact, for high speeds, this assumption could not be valid, but it will affect the results only at the beginning of meshing. However, it is more relevant to see what happens near the middle of meshing, and therefore, the obtained results will not be influenced by this assumption). As meshing progresses, the volume $V$ of the fluid in the cavity is seen to decrease by a volume $v$. The difference $(V-v)$ (for an incompressible fluid: e.g. oil) flows to another inter tooth (radially) and outwardly (axially). Then, the wheel tooth begins to leave the pinion inter tooth, a vacuum is created within the cavity and the fluid that may be made of oil, air or a mixture of both, penetrates until separation, on recess. Some of the fluid is expelled by the tooth during compression flows, the other part escapes to another pinion inter tooth.

\section{Geometric study}

The study is limited to the case of gears whose teeth are the involutes. The points describing the profile of the tooth flank are given by equation (1).

$$
\left\{\begin{array}{l}
x=\frac{r b}{\cos (t)} \times \cos (\tan (t)-t) \\
y=\frac{r b}{\cos (t)} \times \sin (\tan (t)-t)
\end{array}\right.
$$

where:

$r b$ : base circle radius, $M$ : a point on the involute of coordinates $(x, y)$, Figure 2;

$I$ : the tangent at the base circle and passing through $M$, Figure 2;

$t$ : angle between $O M$ and $O I$.

The data used in this paper are selected from [15], Table 1, or from [8], Table 2, with the aim to compare 
Table 2. Gear 2.

\begin{tabular}{cccccc}
\hline & $r p$ & $m$ & $\alpha$ & $x$ & $b(\mathrm{~mm})$ \\
\hline Pinon & 152 & 4 & $20^{\circ}$ & 0 & 30 or 60 or 100 \\
wheel & 152 & 4 & $20^{\circ}$ & 0 & 30 or 60 or 100 \\
\hline
\end{tabular}

Table 3. Internal gear 3 .

\begin{tabular}{lccccc}
\hline & $r p$ & $m$ & $\alpha$ & $x$ & $b(\mathrm{~mm})$ \\
\hline Pinon & 100 & 10 & $20^{\circ}$ & 0 & 100 \\
Internal wheel & 200 & 10 & $20^{\circ}$ & 0 & 100 \\
\hline
\end{tabular}

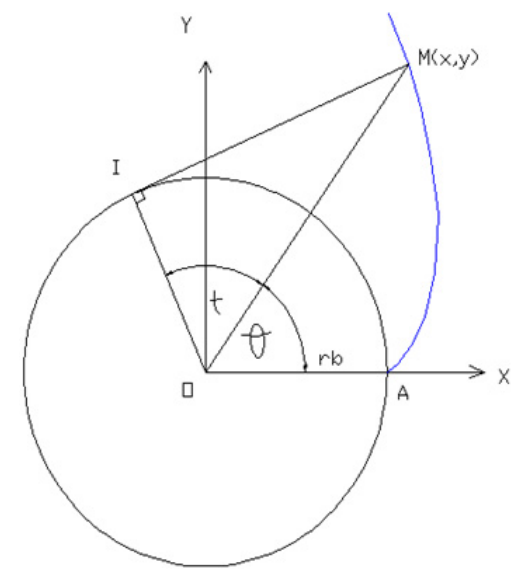

Fig. 2. Involute curve outward from the base circle.

the results with what is published. Table 3 corresponds to internal gear geometry.

\subsection{Angle and time of the tooth-meshing}

The meshing time depends on rotational speed: while the speed is high, meshing time is very short.

To determine the overlap time during meshing (from approach to recess), the priority is to find the angle of approach. This angle may be determined by the intersection between the two outside or addendum circles according to the radii of the two outer circles (Fig. 3) and for internal gear (Fig. 4).

The coordinates of $P e$ approach point and $P s$ recess point are respectively $(x e, y e)$ and $(x s, y s)$ :

$$
R_{a 1}^{2}=x_{e}^{2}+y_{e}^{2} ; \quad R_{a 2}^{2}=x_{e}^{2}+\left(a-y_{e}\right)^{2}
$$

Then

$$
R_{a 2}^{2}=R_{a 1}^{2}-y_{e}^{2}+\left(a-y_{e}\right)^{2}
$$

and

$$
R_{a 2}^{2}=R_{a 1}^{2}+a^{2}-2 a y_{e}
$$

So

$$
\left\{\begin{array}{l}
x_{e}=-\sqrt{R_{a 1}^{2}-\frac{\left(R_{a 1}^{2}-R_{a 2}^{2}+a^{2}\right)^{2}}{4 a^{2}}} \\
y_{e}=\frac{\left(R_{a 1}^{2}-R_{a 2}^{2}+a^{2}\right)}{2 a}
\end{array}\right.
$$

with $R_{a 1}$ : Outer radius of the pinion; $R_{a 2}$ : Outer radius of the gear.

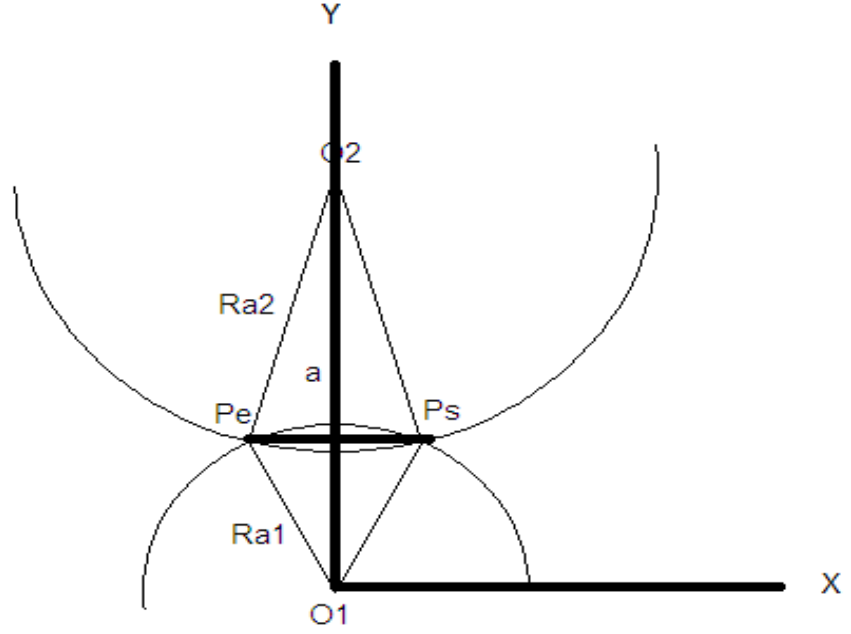

Fig. 3. Starting and end meshing: gear 1.

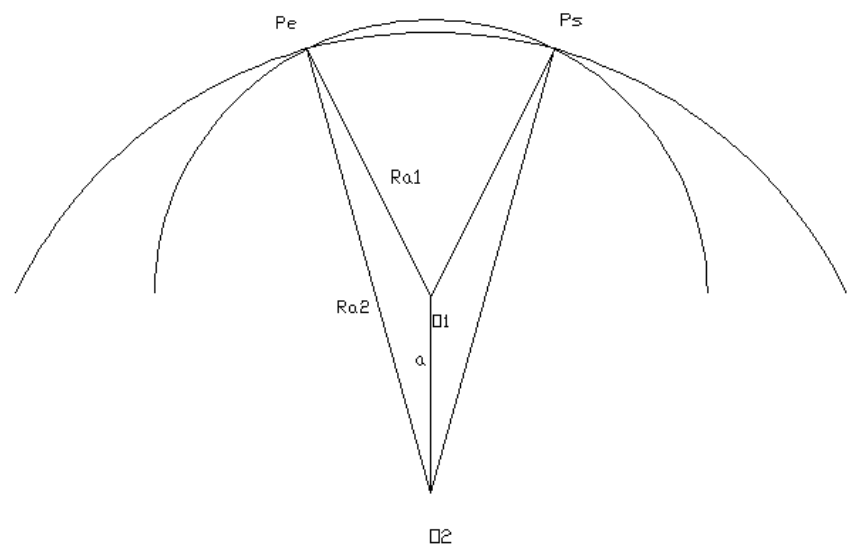

Fig. 4. Starting and end meshing: internal gear 3.

And the coordinate origin is $O_{1}$.

For internal gear

$$
\left\{\begin{array}{l}
x_{e}=-\sqrt{R_{a 1}^{2}-\frac{\left(R_{a 1}^{2}-R_{a 2}^{2}+a^{2}\right)^{2}}{4 a^{2}}} \\
y_{e}=-\frac{\left(R_{a 1}^{2}-R_{a 2}^{2}+a^{2}\right)}{2 a}
\end{array}\right.
$$

The approach angle is given by:

$$
\text { meshing ang }=2 \tan ^{-1}\left(-\frac{x_{e}}{y_{e}}\right)
$$

It is found that this angle depends on gear geometry (outer radii and center distance), whereas the approach time depends on geometry and rotational speed.

For a fixed pitch radius, if the module is increased the teeth number is automatically reduced and the outer radius is increased, increasing the approach angle and consequently the time of approach.

It should be also noted that for internal gears meshing angle is more important and causes a higher engagement time.

Table 4 presents the result angle and time meshing. 
Table 4. Angle and time meshing.

\begin{tabular}{lccc}
\hline & $\begin{array}{c}\text { Speed } \\
\text { pinion }(\mathrm{rpm})\end{array}$ & $\begin{array}{c}\text { Meshing } \\
\text { angle }(\mathrm{deg})\end{array}$ & $\begin{array}{c}\text { Time } \\
\text { meshing }(\mathrm{s})\end{array}$ \\
\hline \multirow{3}{*}{ Gear 1} & 3000 & 57 & 0.1815 \\
module $=10$ & 5000 & 57 & 0.1089 \\
& 10000 & 57 & 0.0544 \\
& 20000 & 57 & 0.0272 \\
\hline \multirow{3}{*}{ Gear 1} & 3000 & 41 & 0.1307 \\
module $=5$ & 5000 & 41 & 0.0784 \\
& 10000 & 41 & 0.0392 \\
& 20000 & 41 & 0.0196 \\
Gear 2 & 3000 & 26 & 0.0828 \\
& 5000 & 26 & 0.0497 \\
& 10000 & 26 & 0.0248 \\
Internal & 20000 & 26 & 0.0124 \\
gear 3 & 3000 & 100 & 0.3213 \\
& 5000 & 100 & 0.1928 \\
& 10000 & 100 & 0.0964 \\
& 20000 & 100 & 0.0482 \\
\hline
\end{tabular}

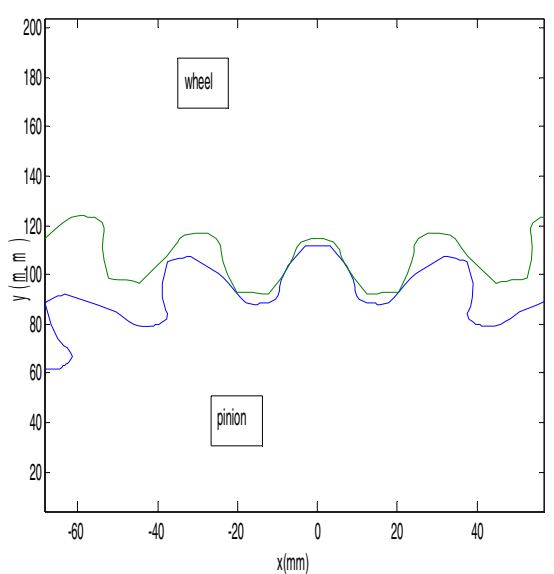

Fig. 5. Pinion and gear positions.

\subsection{Leak surfaces and trapped volumes}

Figure 5 presents pinion and gear positions for gear 1 .

The pinion centre is $(0,0)$ and the wheel one is $(0, a)$ where $a$ is the centre distance.

To study the behaviour of the trapped fluid, the attention has to be paid closely to what happens between the teeth. Therefore, and to simplify, the focus will be limited to one inter tooth during meshing. Rotating this inter tooth (Fig. 6) around the pinion and wheel axes, their positions are versus rotational angle (Fig. 8).

The initial position which corresponds to the tooth position of the symmetrical wheel with respect to the $y$-axis is then taken.

The initial theoretical position is symmetrical with respect to the y-axis of inter tooth. In reality the inter tooth linked to the pinion assumed driving touches on one side of the wheel tooth according to the direction of rotation. A correction of this position is taken into account.

The control volume and leak surfaces, radial and axial, are presented (Figs. 8 and 9).
The radial leak surfaces are between the tooth profile and that of the deddendum. To simplify, it was decided to consider the smallest distance between the profiles. The axial leak surface corresponds to the yellow surface on Figure 9. The axial leak surfaces are numerically integrated. Concerning the trapped volume fluid, it corresponds to the values taken by the axial leak surface multiplied by gear face width for cylindrical spur gears.

Results of radial leak surfaces $S r 1$ and $S r 2$ and axial (for gear 1 and 2 and internal gears) are shown in the (Figs. 10 and 11).

For spur-gears case study, the first minimum distances between the flanks of inter tooth are calculated numerically, then they are multiplied by the face width to obtain the radial leak surfaces $S r 1$ and Sr2. The minimum distances calculated are used to determinate the points on tooth profiles and limit the portions of tooth profiles in contact with the fluid. These portions are numerically controlled and together form a polygon. Axial leaks surfaces $S a$ are obtained by numerical integration of the polygon.

\section{Discretization influence}

The discretization impact on obtained results for radial leak surfaces and on the variation of the trapped fluid volume is analysed. The first factor is the number of points taken on each teeth flank $(N p t)$. The higher this number is, the finer mesh is. The second factor is the number of positions obtained by dividing the approach angle into a number of equal angles $\Delta \theta(N p s)$.

Presented results are for the gear 1, Nps and Npt and chosen as follows:

- Npt takes the values of 10, 100, 200, 500, 1000 and 2000 with fixed Nps at 40 .

- Nps takes the values 20,40, 80, 160, 320 and 640 with $N p t$ fixed $(N p t=1000)$.

The results obtained for $S r 1, S r 2$ and the volume $V$ are presented in Figures 12 and 13.

From a 1000 number of points on each flank profile the axial and radial leak surfaces curves stabilize (without visual disturbances....).

Concerning the number of positions the axial and radial leak surfaces with the data mentioned above were calculated and the influence on the geometry was analysed (Fig. 14).

The computing time for 640 positions and with the data above is about $35 \mathrm{~min}$ while this time is only $5 \mathrm{~min}$ with 20 positions.

By increasing the number of positions (by dividing the approach angle a higher) the axial leaks surfaces curves present weak variations in amplitude but with different steps.

It can be said that the number of $\Delta \theta$ does not have much influence on the axial and radial leaks surfaces curves. 


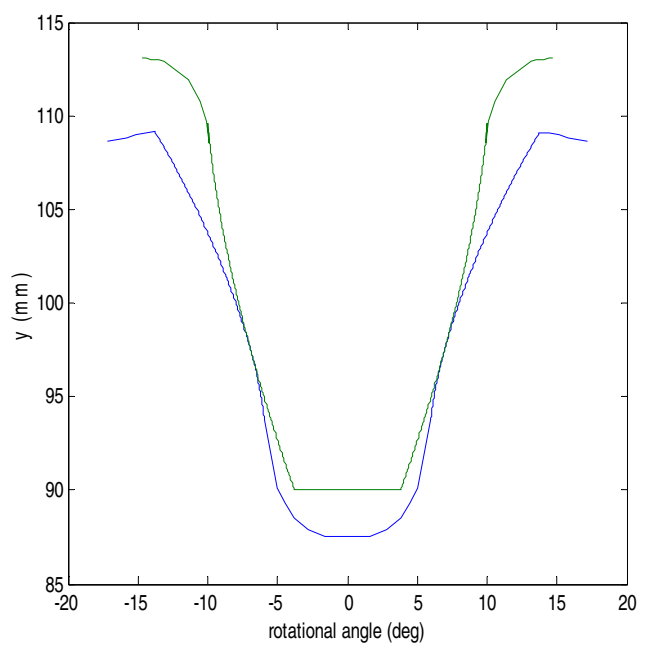

(a) gear \#1

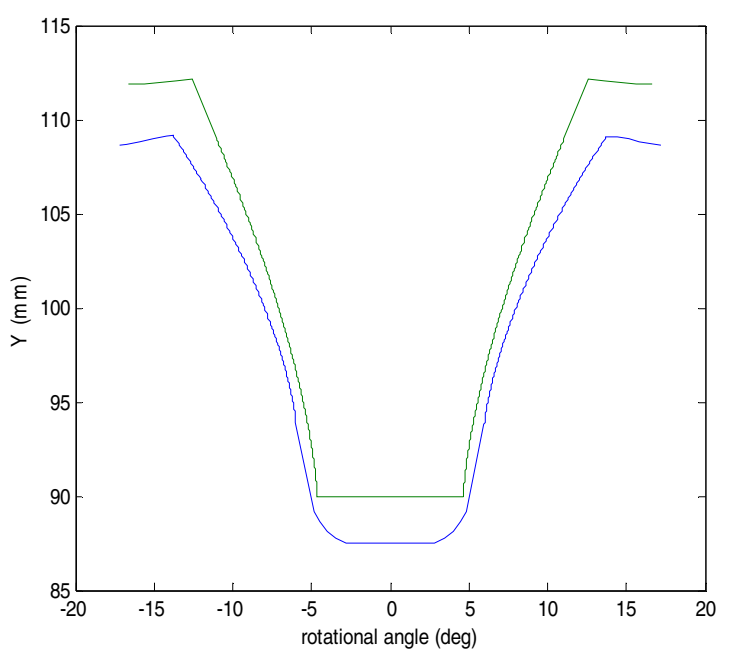

(b) internal gears \#3

Fig. 6. Initial position of inter tooth.

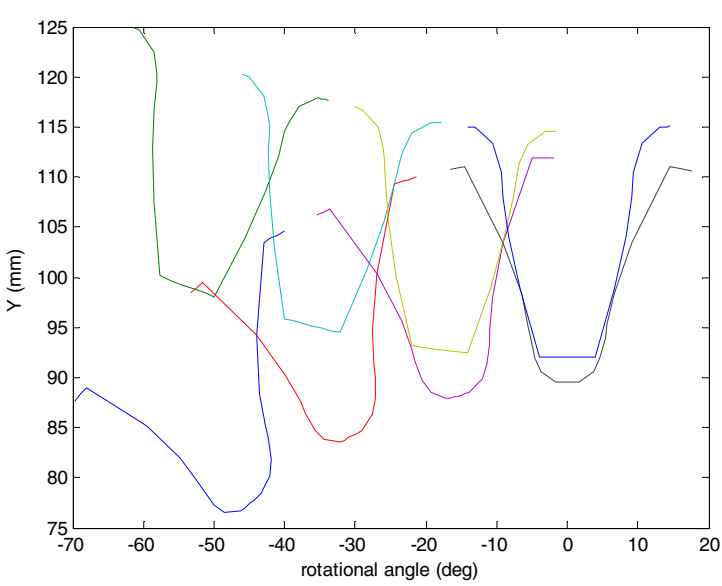

(a) gear \#1

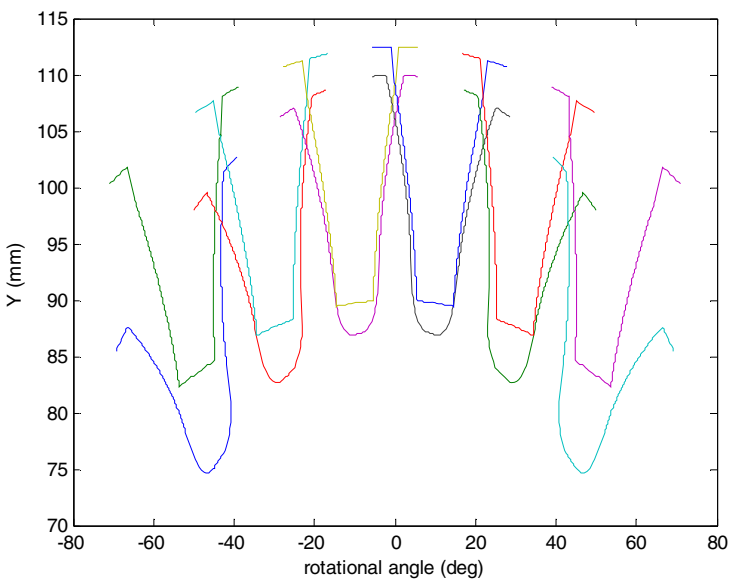

(b) Internal gear \#3

Fig. 7. Successive positions of inter tooth.

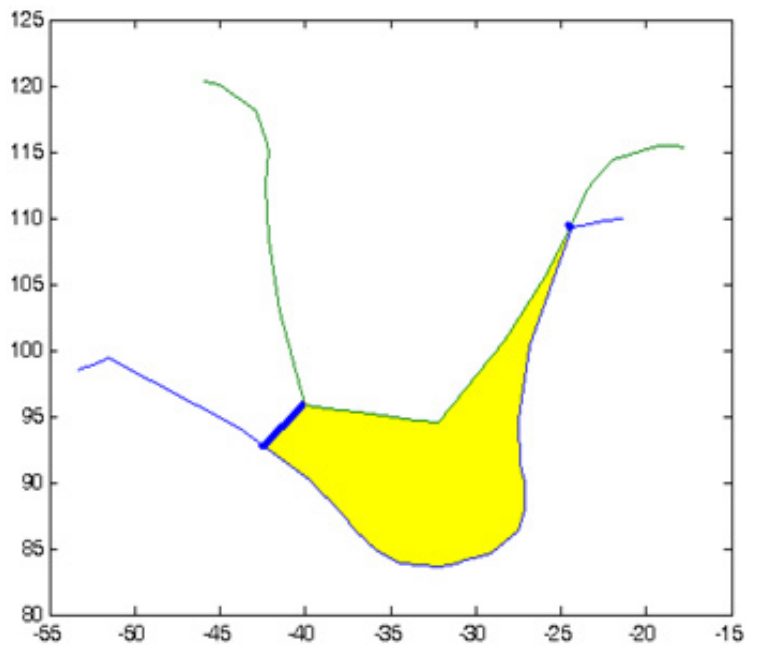

Fig. 8. Intermediate position of inter tooth (gear 1).

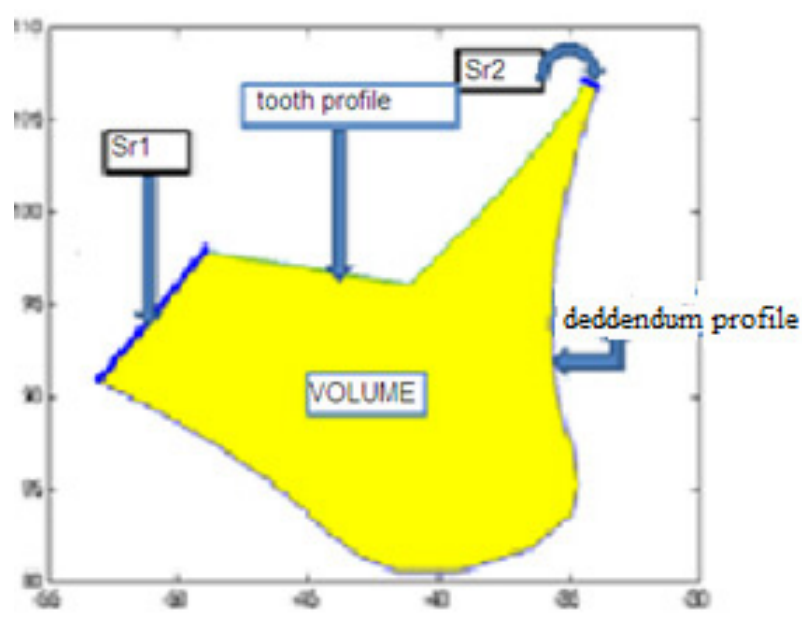

Fig. 9. Intermediate position of inter tooth; isolated trapped volume. 


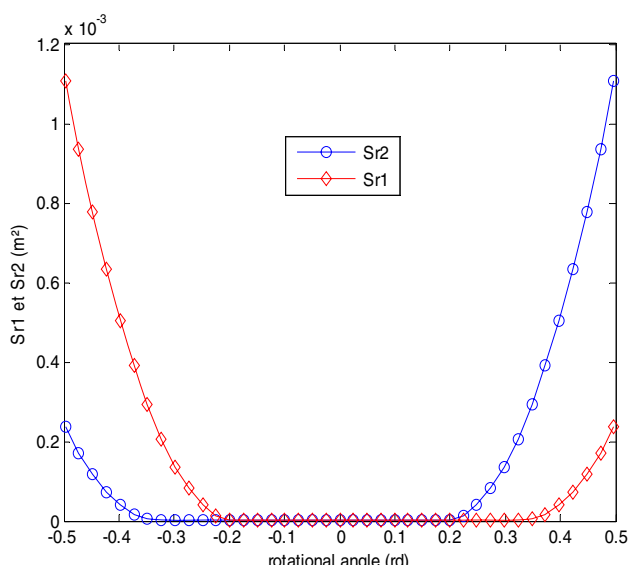

(a) gear \#1

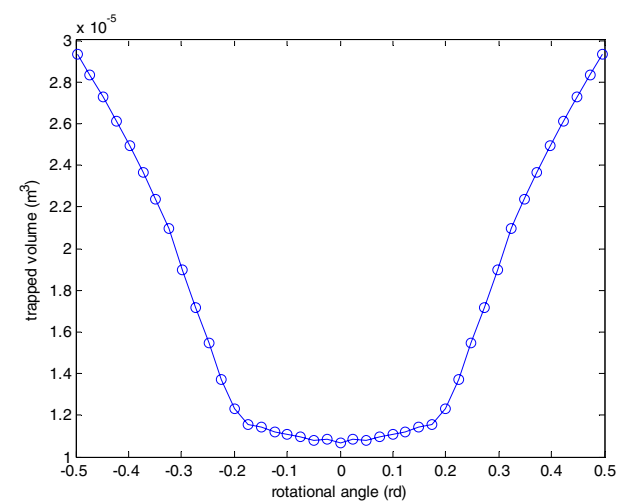

(a) gear \#1

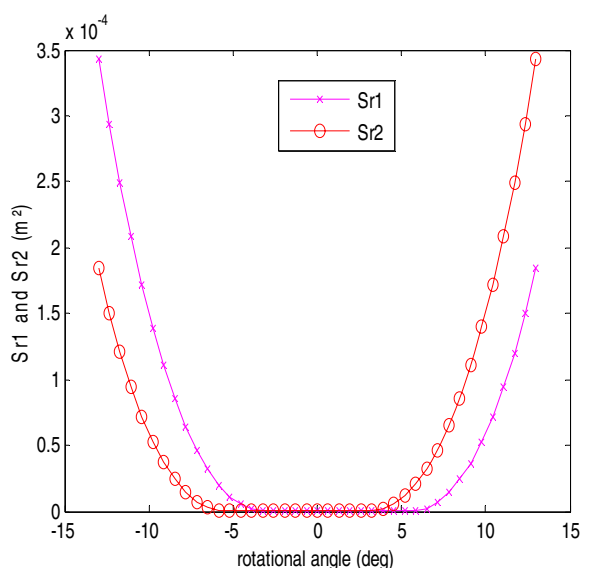

(b) gear \#2

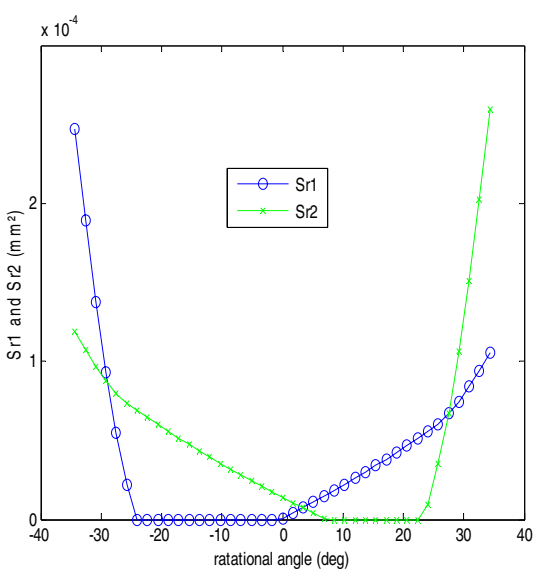

(c) Internal gear \#3

Fig. 10. Radial leak surfaces.

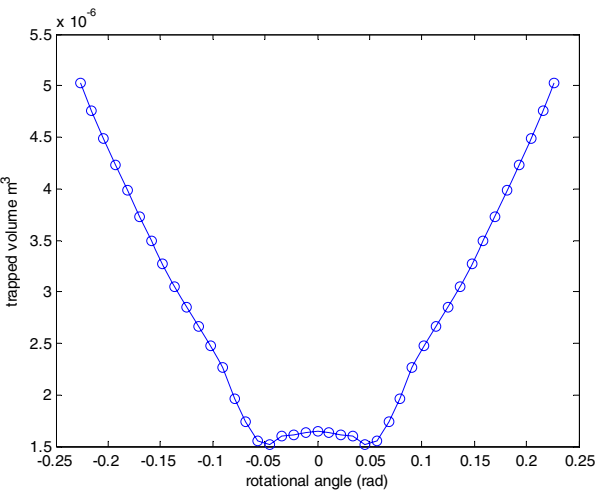

(b) gear \#2

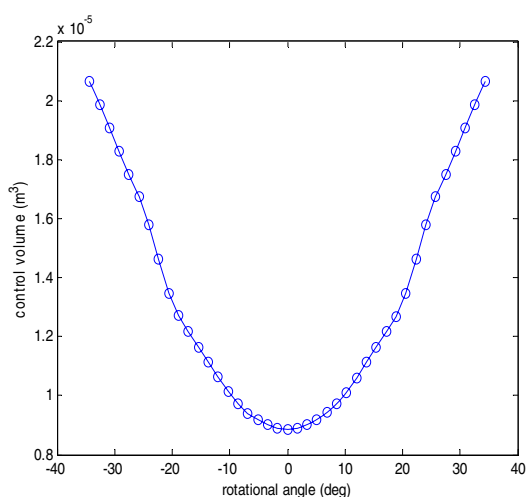

(c) Internal gear \#3

Fig. 11. Trapped volume (axial leak surfaces $* b$ ).

\section{Module influence on the leak surfaces and control volume}

The results obtained in Figure 15 are for gear 1 with different modules. It is known that when the module is reduced the number of teeth increases and the inter tooth decreases. It is confirmed by shown results. It must be also taken into account during the power loss calculations that the trapping phenomenon is repeated as many times as the number of teeth on the pinion for each revolution. It is also noticed that in the vicinity of the angle 0 (degree), the axial leak surfaces are distinctly different unlike the radial leak surfaces.

\section{Influence of the addendum modification coefficient on the leak surfaces and control volume}

The data for Figure 16 are the characteristics of gear 1 with the addendum modification coefficients for the pinion and the wheel $(+0.2$ and -0.2$),(+0.4$ and -0.4$)$ and $(+0.6$ and -0.6$)$ and the center distance fixed. From these results it can be concluded that when the addendum modification coefficient is increased, the axial leak surfaces decrease. Concerning the radial leak surfaces, they are less influenced.

\section{Pressure angle influence on the leak surfaces and control volume}

The pressure angle influence is presented in Figure 17. The pressure angle does not influence the results on the radial leak surfaces. On the contrary, the axial leak surfaces increase when the pressure angle decreases.

\section{Influence of the addendum reduction coefficient $\left(\mathrm{K}^{*} \mathrm{~m}\right)$ on the leak surfaces and control volume}

Table 5 shows the values of $h a, h f$ and $c$ for different values of $K$, where: $h a$ is the addendum coefficient, $h f$ is the deddendum coefficient and $c$ is gear clearance between tooth tip and wheel root. 

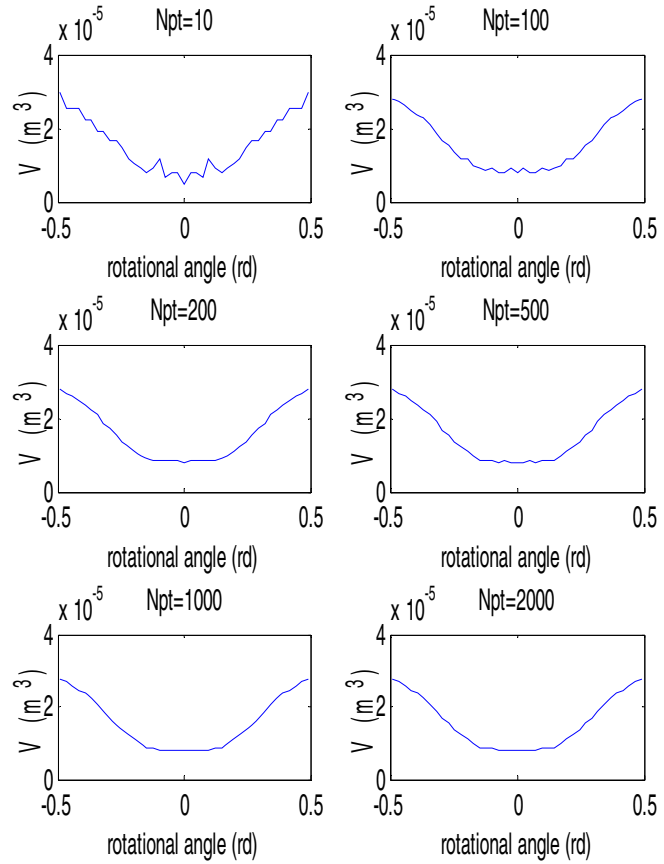

Fig. 12. Influence of mesh density on axial leak surfaces (gear 1).
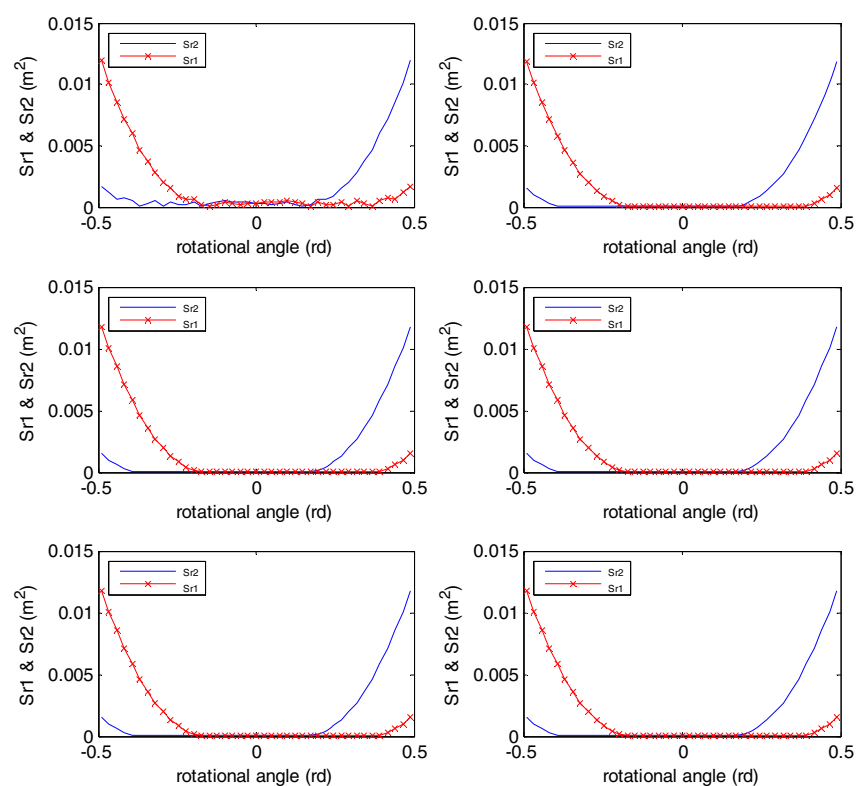

Fig. 13. Influence of mesh density on radial leak surfaces (gear 1).
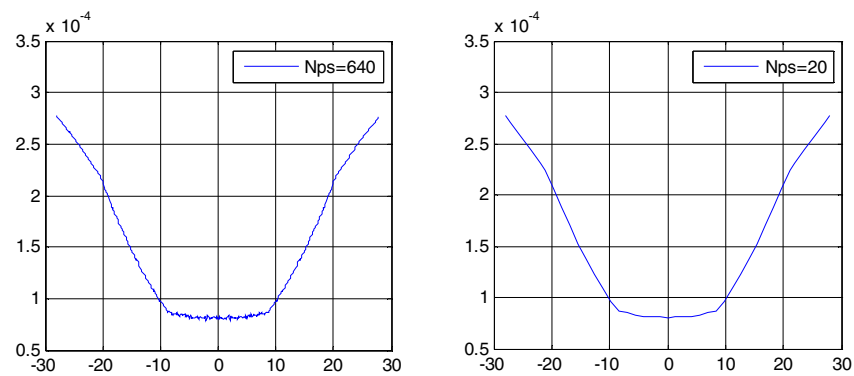

Fig. 14. Axial leak surfaces, gear $1, N p s=20$ and 640 .
Figure 18 shows that the addendum reduction coefficient only influences the axial leak surface. This is compatible with the fact that, $(K * m)$ controls the gear clearance between the tooth tip and wheel root.

\section{Face width influence on the leak surfaces and control volume}

In order to underline the influence of the face width $b$ on the leak surfaces and control volume, different values were given to the face width $b$ and the results are presented in Figure 19. The radial leak surfaces and control volume increase when the face width increases. This result is confirmed by references $[8,14]$.

\section{Discussion}

Sr1 and Sr2 are therefore proportional to the face width, as shown in Figure 19. The face width does not intervene in $S a$ calculation but the volume control is obtained by multiplying $S a$ by face-width (for spur gears). This may explain the fact that by increasing face width, the volume increases; but axial surfaces of discharges remain constant. Therefore, a large amount of fluid is compressed and it will have more power losses by trapping phenomenon. This conclusion is already confirmed by previous studies references $[8,14]$.

It is clear that the compression of a given volume of fluid pushes the fluid to escape from the control area through leak surfaces. This pressure will be greater if the leak surfaces are smaller.

To determine the volume control, Seetharaman and Kahraman [14] used analytical formula (some approximations have been made). They gave average values of the varying volume control function of time or rotation angle. In the present study, numerical calculation of geometry variation of meshing is shown.

\section{Conclusion}

This study targeted the numerical modeling to simulate the oil trapping between the inter teeth during meshing of internal and external spur gear. To meet this need a program was developed.

Modeling allowed identifying the volume of trapped fluid and knowing at every time its free borders and those in contact with teeth.

Afterwards, a study of the impact of the discretization was carried out and showed the importance of the number of points taken on each tooth profile. Finally, the influence of design parameters of gears as module, pressure angle and addendum modification coefficient on the radial and axial leak surfaces was presented. In the design parameters, the module is the critical factor influencing result.

Then, it was shown that the rotational speed as an operating parameter clearly influences the approach time. 


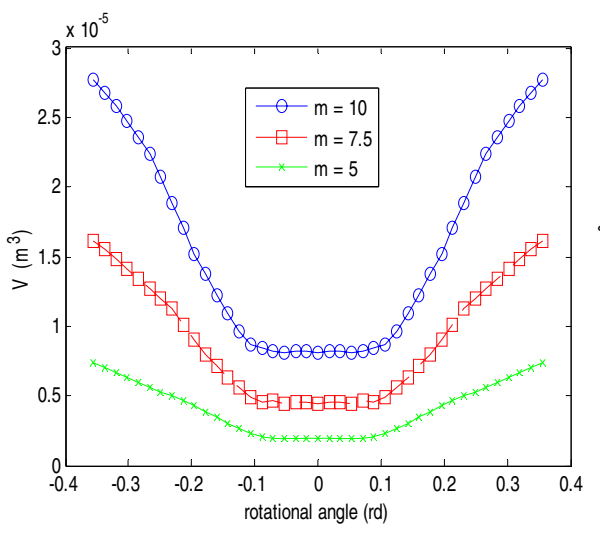

(a) axial leak surfaces

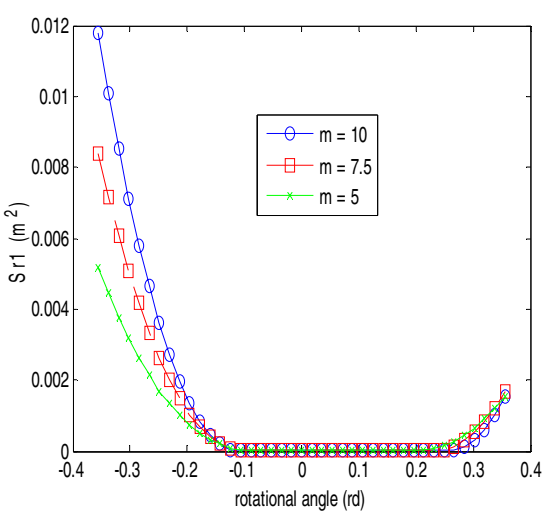

(b) radial leak surfaces $\mathrm{Sr} 1$

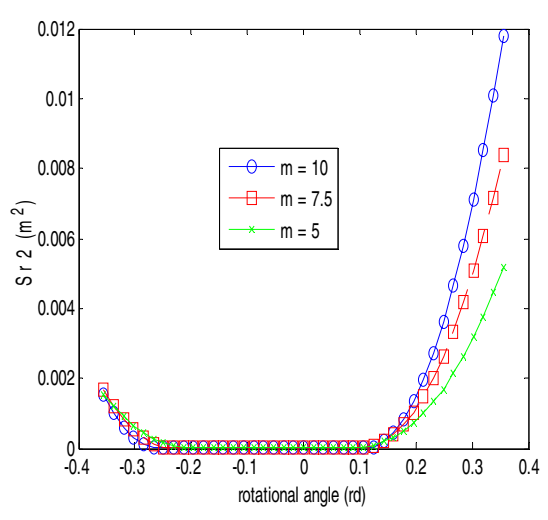

(c) leak surfaces $\mathrm{Sr} 2$

Fig. 15. Leak surfaces, gear $1, m=5,7.5$ and $10 \mathrm{~mm}$.

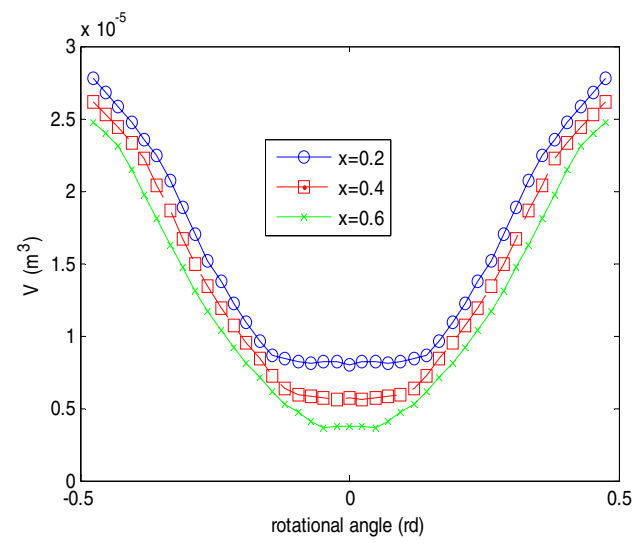

(a) axial leak surfaces

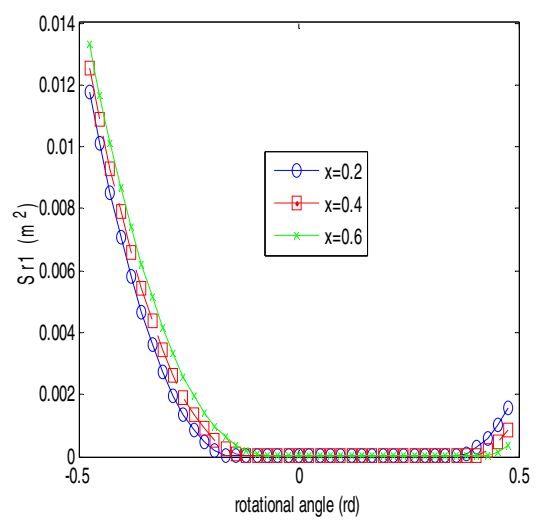

(b) radial leak surfaces $\mathrm{Sr} 1$

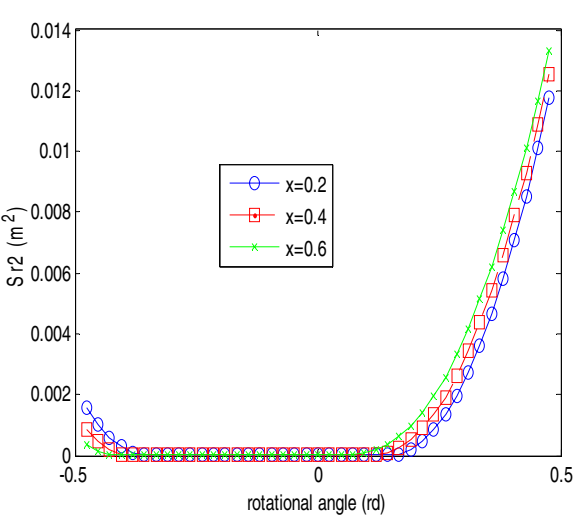

(c) leak surfaces Sr2

Fig. 16. Leak surfaces, gear $1, x=0.2,0.4$ and 0.6 .

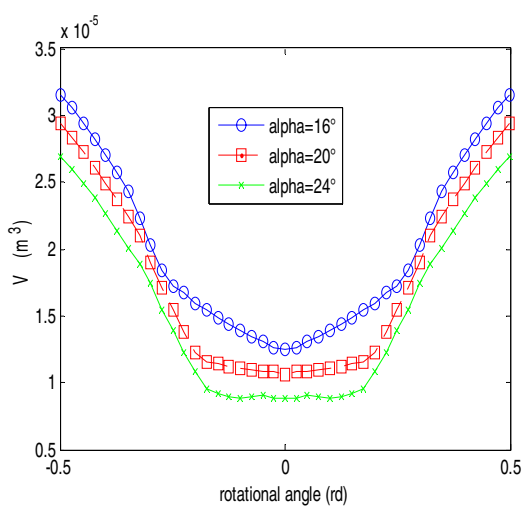

(a) trapped volume

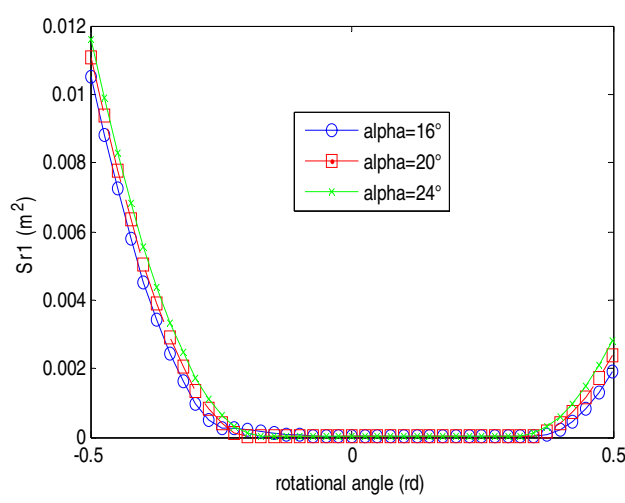

(b) radial leak surfaces $\mathrm{Sr} 1$

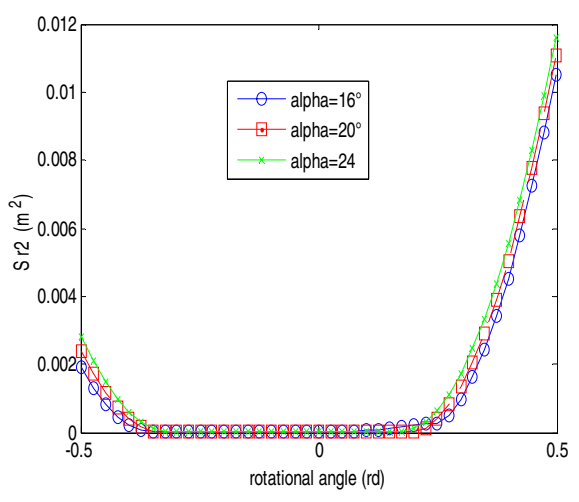

(c) radial leak surfaces Sr2

Fig. 17. Trapped volume and leak surfaces, gear 1 , alpha $=16^{\circ}, 20^{\circ}$ and $24^{\circ}$. 


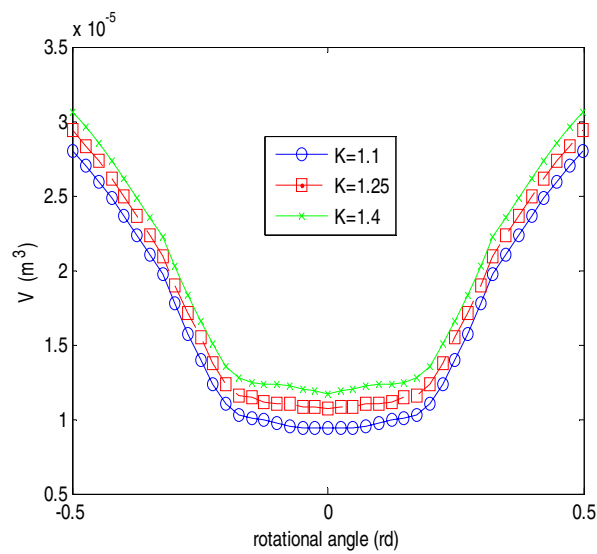

(a) trapped volume

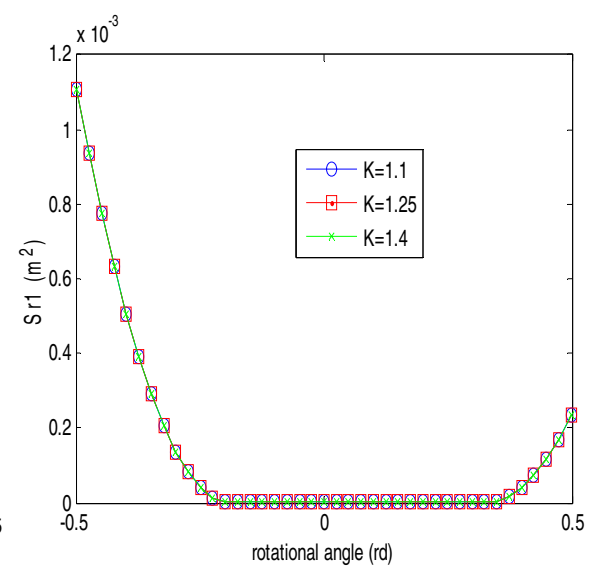

(b) radial leak surfaces $\mathrm{Sr} 1$

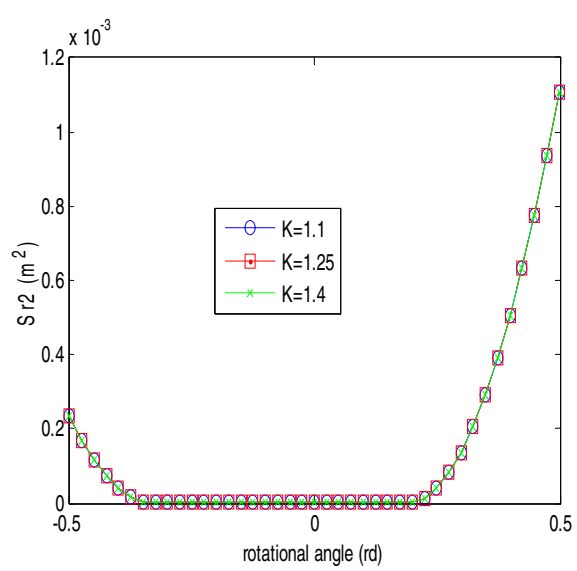

(c) radial leak surfaces $\mathrm{Sr} 2$

Fig. 18. Trapped volume and leak surfaces, gear $1, K=1.1,1.25$ and 1.4.

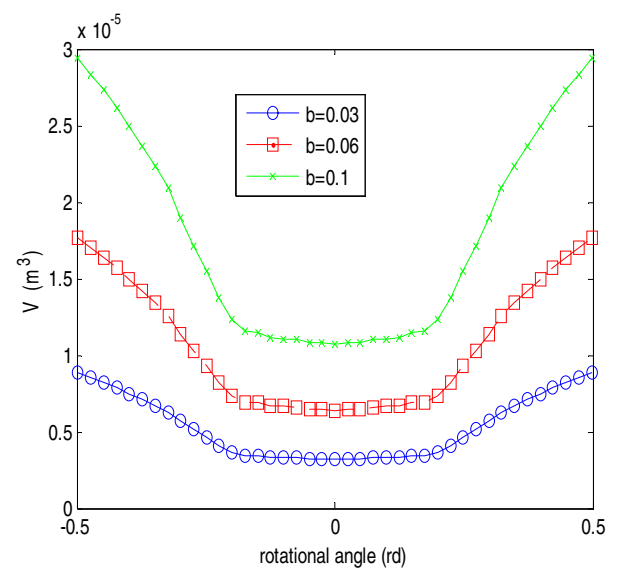

(a) trapped volume

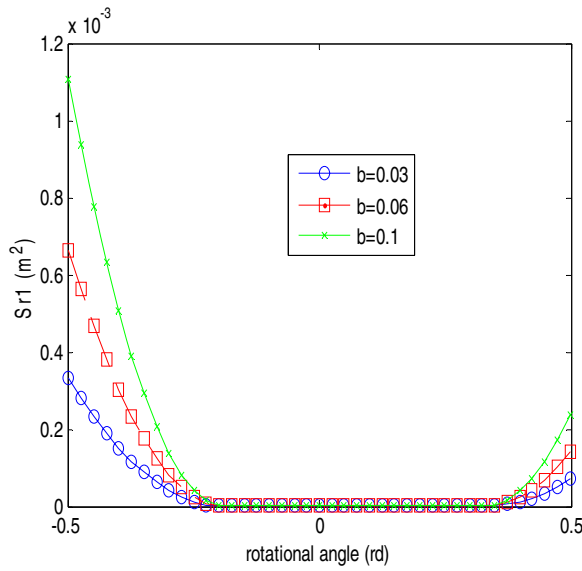

(b) radial leak surfaces $\mathrm{Sr} 1$

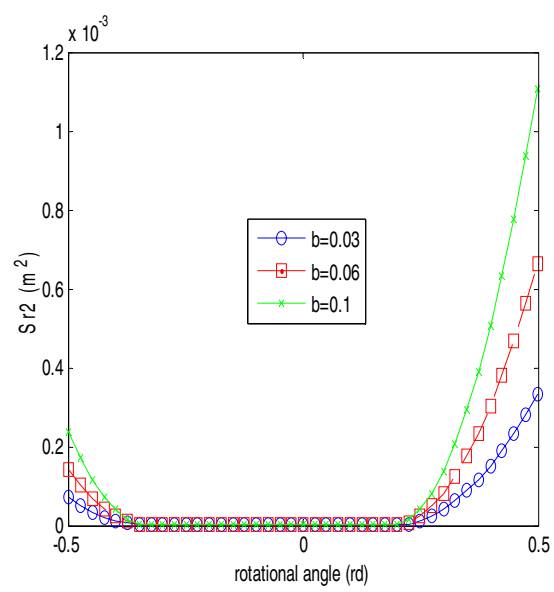

(c) radial leak surfaces $\mathrm{Sr} 2$

Fig. 19. Trapped volume and leak surfaces, gear $1, b=0.03,0.06$ and $0.1 \mathrm{~m}$.

Table 5. Values of $h a, h f$ and $c$ for different values of $K$.

\begin{tabular}{lccc}
\hline & $h a$ & $h f$ & $c$ \\
\hline$K=1.1$ & $0.88^{*} \mathrm{~m}$ & $1.1^{*} \mathrm{~m}$ & 0.22 \\
$K=1.25$ & $1^{*} \mathrm{~m}$ & $1.25^{*} \mathrm{~m}$ & 0.25 \\
$K=1.4$ & $1.12^{*} \mathrm{~m}$ & $1.4^{*} \mathrm{~m}$ & 0.28 \\
\hline
\end{tabular}

This allows the designer to take into account the influence of these parameters during design. This study can also be used to improve the efficiency of lubrication and cooling in gear drives.

Future work will focus on the model to determine the pressure of the trapped fluid and estimate the trapped losses.

\section{References}

[1] Y. Diab, F. Ville, P. Velex, Prediction of Power Losses Due to Tooth Friction in Gears, Tribology Transactions 49 (2006) 260-270
[2] S. Seetharaman, A. Kahraman, A Windage Power Loss Model For Spur Gear Pairs, Tribology Transactions 53 (2010) 473-484

[3] Y. Ariura, T. Ueno, S. Sunamoto, The Lubricant Churning Loss in Spur Gear Systems, Bull. JSME 16 (1973) 881-890

[4] C. Changenet, G. Leprince, F. Ville, P. Velex, A Note on Flow Regimes and Churning Losse Modeling, J. Mech. Design 133 (2011) 121009

[5] M.J. Pechersky, M.J. Wittbrodt, An analysis of fluid flow between meshing spur gear teeth, In Proceedings of the 5th ASME Power Transmission and Gearing Conference, Chicago, 1989, pp. 335-342.

[6] J.D. Smith, Gear noise and vibration, Marcel Dekker, New York, 1999

[7] H. Houjoh, K. Umezawa, The sound radiated from gears (On the existence aerodynamic sound), JSME Int. J. 30 (1987) 153-160 
[8] Y. Diab, F. Ville, H. Houjoh, P. Sainsot, P. Velex, Experimental and numerical investigations on the airpumping phenomenon in high-speed spur and helical gears, J. Mech. Eng. Sci. 219 (2005) 785-800

[9] Y. Diab, Analyse des Pertes de Puissance dans les Transmissions par Engrenages à Grande Vitesse, applications aux réducteurs industriels et aux machines textiles, Ph.D. thesis, INSA de Lyon, 2005

[10] A. Wimmer, B.R. Höhn, K. Michaelis, Low Loss Gears, Gear Technology (2007) 28-35

[11] L. Magalhaes, R. Martins, C. Locateli, J Seabra, Influence of tooth profile on gear power loss, 3rd International Conference on Integrity, Reliability and Failure Porto/Portugal, 20-24 July 2009
[12] F. Concli, Efficiency of Gear Transmissions and CFD Analysis of the Load Independent Power Losses, Ph.D. Thesis, Politecnico di Milano, 2013

[13] W. Mauz, Hydraulische Verluste bei Tauch-und Einspritzschmierung von Zahnradgetrieben/universitat Stuttgart, 1985, - Dissertation

[14] S. Seetharaman, A. Kahraman, Load-Independent Spin Power Losses of a Spur Gear Pair: Model Formulation, ASME J. tribology 131 (2009) 022201

[15] G. Henriot, Engrenages : conception, fabrication, mise en œuvre, $8^{\text {ème }}$ édition, Dunod, 2007 